\title{
A factorial study of institutional distinction and it's relation with counter productivity behaviors *Dr. Bassma Ibrahim Abdel Bassir
} Abstract:

The study aims at analyzing factors of the institutional excellence and it's relation with counterproductive work behaviors inside the department of youth and sport at Minia governorate.

The community of the study is represented in sport specialists in the department of youth and sport at Minia governorate representing in (the chief specialists, the first-class specialist, the second-class specialist, the third-class specialist) of (820) specialists. The researcher selected the sample randomly from the study community of (182) specialists with a percentage of (22.19\%) from the study community as a whole.

The researcher used (2) questionnaires, the first one aims at recognizing factors of the institutional excellence in the department of youth and sport at Minia governorate

The most important findings: the questionnaire of the institutional excellence settled on (7) factors that were accepted and named according to the sore of eignvalue and the percent of the explained variance. The questionnaire of counterproductive work behavior settled on (2) factors that were accepted and named according to the sore of eignvalue and the percent of the explained variance, the availability of the institutional excellence inside the department of youth and sport at Minia governorate, the availability of counterproductive work behaviors whether targeting the organization or the individuals in work inside the department of youth and sport at Minia governorate. There is a statistically significant reverse correlation between the institutional excellence and counterproductive work behaviors inside the department of youth and sport at Minia governorate.

\section{Introduction and problem:}

Recently, sport organizations seek to achieve the possible high level of quality, perfection and excellence in performance arriving the top, since this becomes urgent and necessary matter and requirement that

"by applying on the department of youth and sport at Minia governorate.

Assiut Journal For Sport Science Arts 
can't be overlooked or not concerned with, since we live in an age of speed development and change, the age of huge knowledge revolution and terrible technological and technical advancement in different productive fields, an age won't admit but with competent distinguished whether they are individuals or institutions. Under the competition in achieving pioneering and forefront in distinction and quality in different work fields, this can't be achieved unless there is a competent and efficient management improving functioning it's available resources through it's application of modern management thinking that makes it confronts challenges.

Institutional excellence expresses a management intellectual and philosophical type relying on a method related with how to achieve tangible results of the organization to achieve balance in satisfying all parties needs whether from stakeholders or the society as a whole in the frame of continuous learning, creativity and improvement culture (El Sayed 2007: 114).
The researcher sees that the institutional excellence means that the institutional performance surpasses the expected performance whether inside the institution itself or surpasses it's counterparts in field reality or surpasses the expectancies of institution beneficiaries.

$$
\text { Al Salmi }
$$
indicates that the concept of the institutional excellence sits on top developments in which knowledge revolution produced. It is a comprehensive concept for crystallizing the main purpose of management in organizations on one hand, and determining the main trait in which it should be characterized with on the other hand (Al Salmi 2012: 7).

This is what Hassan study (2016) achieved where it indicated that there is a direct correlation relationship between dimensions of institutional excellence achieving the competitive advantage and the efficient role in which the institutional excellence plays in achieving this , as well as Hamouda study (2009) indicated that the excellence continuity in 
organizations need to management continuity in it's position in a way enabling to build the strategy, develop general policies and plans that work on improving the circumstances of morale work environment allowing the mutual confidence between employees and management and reflecting this on the institutional performance .

AlKhalifa

emphasizes that the institutional excellence of the organization as a whole is a product reflecting the extent of the organization response efficiently for the circumstances and variants of the internal and external environment, as well as the expectancies of parties of the same relationship in this environment, since there are several parties that influence in determining vision, message and goals of the organization whether they were strategically or tactically, as well as determining it's general policy and what is accepted or unaccepted in performance methods to achieve these goals (AlKhlifa 2015 : 73).

This is what Merghany study (2015) confirmed in which its findings showed the necessity of adopting institutional excellence standards that contribute in presenting the most important improvement opportunities specific with work organization in which the top management can determine the most important issues that should be treated and improved clearly and continuously in work system that in turn leads to improve results and achieve the lasting success

The concept of institutional excellence emanates from two basic facts in modern management, the first is that the purpose of the successful management is to seek achieving excellence meaning accomplishing unprecedented results surpassing all it's competitors but on itself, the second is that all emanate from the management of works and decisions and what it approves from systems and effectiveness should be characterized with excellence, this means high and complete quality that leaves no way of fault or deviation and creates opportunities to execute the right works rightly and completely (AlSalmi 2012: 8) . 
Institutional excellence includes a set of components in which each one is considered a field to achieve excellence, the most important ones are (strategic excellence, leadership excellence, cognitive excellence, financial excellence). The most prominent features of institutional excellence are accepting difficult works, one of the most important sources of the institutional excellence is development opportunities, speed learning, improving processes, commencement of work from nothing, taking difficulties and organization taking of crises, since it's coping contributes in polishing organization capacities and it's excellence. (Elnosour 2010: 33)

This is what Eglelaar study (2014) indicated and recommended the importance of determining the vital areas that are necessary to improve service delivery and achieve excellence in performance through using models of institutional excellence, applying and investigating it inside the organization to determine characteristics of institutional excellence model which will enhance institutional performance in offering the service.

Concerning with studying human behavior became urgent necessity for being helps in the ideal use of human organizations resources to achieve high productivity. Since there is a mutual influence between the human behavior and organizational behavior, the individual performance is a product of his ability on his performance and desire in work. If the individual feels that the organization appreciates him and his efforts, he will not suffice to perform his formal role only, but it will extend to perform a volunteer further role in which the scientists called the organizational citizenship. (Alsous, 2008: 33).

This is what Nafari, et al.,2013) study showed and its results revealed that the procedural, distributional and interaction justice has a reverse effect on counterproductive work behaviors.

But if he feels that the organization doesn't appreciate his efforts and doesn't achieve his goals, he will take counterproductive behaviors 
hurting the organization or it's employees interests. The latter influences productivity and costs organizations a lot of money. Today, counterproductive work behaviors are considered important issues in the world for it's serious consequences on organizations and employees (Alsous ,2008: 34).

Several scientists agreed that employees in various institutions practice multiple behaviors that can be classified into three basic classes, the first class is known as In Role Behavior, they are these behaviors that determine the formal role falling under the functional classification. The second class that is commonly named Organization Citizenship Behavior for organizational behavior scientists, they are selective noncompulsory behaviors practicing voluntarily by the employees aiming work interest but they are not fall under the functional classification of the individual. The third class is known as counterproductive work behavior, they are voluntary selective behaviors but hurt work and organization interest
(Becker \& Kernan ,2003: 65), (McShare \& Glinow ,2007: 22), (Rotundo \& Xie, 2008: 859).

Chang \&Smithikarai
(2010) mention that
counterproductive behaviors are a set of behaviors work against organization interest that individuals intend to do and it might affect directly on organization properties or the ability to work with it or through hurting employees, hence reduce it's effectiveness, it may include assaulting colleagues, forging expenses specific reports, damaging and steal (Chang \& Smithikarai, 2010: 1277). This what Gualandri study (2012) confirms that counterproductive work behaviors are intended voluntary in which organization members practice with different motives to hurt general interest of the organization or it's members or it's clients

From a counter view, Nafafri, et al. (2013) sees that employees may practice some counterproductive work behaviors unintentionally or without belief that they are harmful behaviors. Based upon this, these behaviors will be 
explained by the organization management as counterproductive behaviors (Nafafri \&Khalili, 2013: 590). This is accorded with Taylor study (2012) indicating that the most prominent standards to describe counterproductive work behaviors are that the behavior must be voluntary and intended aiming at hurting the organization or it's employees.

Sprung (2011) showed that counterproductive work behaviors don't include the casual out of the individual will such as absence because of ill or slowness in accomplishing the required work because of his losing for the skills necessary for it's accomplishment, so the behavior goal should be recognized so that it can be classified as a counterproductive work behavior or not (Sprung, 2011: 76).

In the light of the above of presenting theoretical frames that dealt with highlighting the importance of achieving the institutional excellence for the organizations inside sport society, through the researcher sense for the importance of youth and sport department at Minia governorate as institutional entity charging of managing sport movement inside Minia governorate and supervising sport plans, programs and projects at Minia governorate.

Through some field visits by the researcher according to her supervision on students at faculty of physical education in the field training, the researcher noticed some deficiencies in managing work inside the department of youth and sport and lowering the level of offering the service for beneficiaries from sport and youth organizations at Minia governorate, as well as a state of complaining, dissatisfaction and fights between employees resulting in the appearance of some negative behaviors by employees at the department whether towards the department or some colleagues.

This is what the study of Abdullah (2017) confirmed finding the weakness of sport specialists responses in the department of youth and sport at Sharkia governorate in all institutional axes indicating that there is a deficiency in applying work system that influences negatively in the ability of meeting needs and 
desires of clients as well as internal systems of work.

Some previous studies related with the present study such as Hassan study (2017) in which it's results found that the moral role of leadership is the most influential role in counterproductive work behaviors, and this is what Awad study (2015) indicated and it's most important results are that the inspire leadership by which the employees perceive is appropriate reversely with the dimensions of counterproductive work behaviors.

Hence the researcher idea was formed in the necessity of studying the factors contributing in achieving institutional excellence of performance inside the department of youth and sport at Minia governorate in a way that can contribute in limiting counterproductive work behaviors that may destroy the organization.

Key terms:

Institutional Excellence:

The Practices that make the institution distinctive in it's performance through functioning the available abilities and resources effectively and distinctively in a way that makes it superior and unique than the rest institutions and this is reflected in how to deal with beneficiaries and how to perform it's activities and processes, preparing it's management and organizational policies and strategies (Gaber, 2012 :42).

\section{Counterproductive Work Behaviors}

which form of protests in members to express their discontent and dissatisfaction inside the organization as an attempt to solve injustice (Kelloway et al.,2010: 18).

The intended behavior by the employees that seeks to hurt the organization and it's members (Rotundo \& Spector, 2010: 491).

\section{Goal of the study:}

The study aims at
analyzing factors institutional excellence and it's effect on factors of counterproductive work behaviors inside the department of youth and sport at Minia governorate.

\section{Questions of the study:}

In the light of the study goal the researcher develops the following questions: 
1- What are the factors necessary for achieving institutional excellence for youth and sport department at Minia governorate?

2- What are the factors that form counterproductive work behaviors inside youth and sport department at Minia governorate?

3- Are factors of intuitional excellence available inside youth and sport department at Minia governorate?

4 - $\quad$ Are there counterproductive work behaviors inside counterproductive work behaviors inside youth and sport department at Minia governorate?

5- is there a statistically significant correlation between the institutional excellence and counterproductive work behaviors inside the department of youth and sport at Minia governorate?

Procedures of the study: Method of the study:

The researcher used the descriptive method for it's appropriateness to achieve the study goal and it's procedures nature by describing what is being, analyzing it and drawing facts from it.

\section{Community and sample of the study:}

The community of the study is represented in sport specialists in the department of youth and sport at Minia governorate representing in (chief specialist, first class specialist, second class specialist, third class specialist) of (820) specialists. The researcher selected the sample randomly from the study community of (200) specialist with a percentage of $(24.39 \%)$ After distributing the questionnaire, the incorrect questionnaires were excluded, hence the number of the study sample was (182) specialists with a percentage of $(22.91 \%)$ from the study community as a whole. The researcher selected (30) specialists for the pilot study and outside the original study sample. Table (1) shows a statement of the number and the percentage for the community and sample of the study (appendix 8).

Firstly: a questionnaire of institutional excellence: (prepared by the researcher)

The researcher read several of the scientific references and previous Arabic and foreign studies in the fields of management and sport 
management

revealing preparing and formulating (56) statements in it's initial form (appendix 2). Then the researcher presented them on a group of experts (appendix 1) in the field of sport management of (7) experts to show the opinion in the extent of it's appropriateness and suitability. (5) statements were deleted that got a percentage of $(70 \%)$ and less of the experts opinions agreement, hence, the questionnaire was prepared and formulated to be in it's final form before conducting the factor analysis consisting of (51) statements (appendix 3). To correct the questionnaire, the researcher suggested Likert triple estimated scale as follows: " verified (3) scores, " somewhat " (2) scores, " not verified (1) score.

The scientific coefficients of the questionnaire:

The researcher calculated the scientific coefficients of the questionnaire as follows (appendix 8 ):

Secondly: the questionnaire of counterproductive work behaviors:

(prepared by the researcher)

The researcher read several of the scientific references and previous Arabic and foreign studies in the fields of management and sport management revealing preparing and formulating (21) statements in it's initial form (appendix 5). Then the researcher presented them on a group of experts

(appendix 1) in the field of sport management of (7) experts to show the opinion in the extent of it's appropriateness and suitability. (2) statements were deleted that got a percentage of $(70 \%)$ and less of the experts opinions agreement, hence, the questionnaire was prepared and formulated to be in it's final form before conducting the factor analysis consisting of (19) statements (appendix 6). To correct the questionnaire, the researcher suggested Likert triple estimated scale as follows: " there are (3) scores, " somewhat " (2) scores, " there is no (1) score.

The scientific coefficients of the questionnaire:

\begin{tabular}{|c|c|}
\hline $\begin{array}{l}\text { The } \\
\text { alculated }\end{array}$ & the \\
\hline $\begin{array}{l}\text { coefficients } \\
\text { questionnaire } \\
\text { (appendix } 8 \text { ) }\end{array}$ & $\begin{array}{l}\text { of } \\
\text { as }\end{array}$ \\
\hline
\end{tabular}

\section{The used statistical method:}

After collecting and tabulated data, the processed it statistically and to calculate the research findings the researcher 
used the following statistical methods:

-Percentage

- correlation coefficient.

-Cronbach Alpha coefficient

- Factor analysis

-Relative

weight

- The percent of mean response- Confidence limits.

The researcher accepted a significance level at (0.05) and the researcher used Spss to calculate some statistical coefficients.

Presenting and discussing the findings:

Responding the first question stating that:

-What are the factors necessary to achieve the institution excellence of youth and sport department at Minia governorate?

The researcher conducted the factorial analysis by using SPSS-Factorial analysis was conducted by the principle component method. After rotation , yielding (7) factors and by taking Guilford criterion (0.3), to select significant saturations, statements were selected that were saturated on more than one factor with nonconvergent values by selecting major saturation and factors in which (3) statements and more were retained with a saturation value of a minimum (0.3) and the statements that got saturation less than (0.3) were deleted that guarantees better factorial purity for factors and the following is a description of these factors (appendix 9)

It is shown from table

(7) That the eigenvalues for all factors are greater than integer and that the factor variance rates for all the derived factors after rotation ranged between (9.08- 11.43), since the first factor explained (11.43), the second factor (11.02), the third factor (10.76), the fourth factor (10.58), the fifth factor (10.56), the sixth factor (9.94), the seventh factor (9.08) and total variance percent of the questionnaire for the derived seven factors was (73.37) (appendix 9).

It is shown from tables (7), (8) that the eignvalue for this factor was (5.83) and that the percent of the explained factorial variance was (11.43), and (9) items were saturated in descending order according to it's saturation value on the factor, hence the researcher suggests naming this factor (excellence of operational performance). 
The researcher attributes this finding to the importance of concentrating on internal and operational processes of work systems in the department of youth and sport at Minia governorate in a form that contributes in reaching excellence in performance. Interest in internal management and technical procedures, rules, mechanisms and methods of work making the department surpass itself and peers (appendix 9).

It is shown from tables (7), (9) that the eignvalue for this factor was (5.62) and that the percent of the explained factorial variance was (11.02), and (8) items were saturated in descending order according to it's saturation value on the factor, hence the researcher suggests naming this factor (excellence of strategic performance).

The researcher attributes this finding to the strategic power in which the department can be characterized of effective indicators for the strategic institutional performance that contributes in achieving competitive advantages and abilities among it's other peers in the case of availability of these factors that concern with the future strategic performance reflecting on the institutional excellence in an attempt to provide these factors so that it can achieve an excellence in the institutional performance (appendix 9) .

It is shown from tables (7), (10) that the eignvalue for this factor was (5.49) and that the percent of the explained factorial variance was (10.76), and (7) items were saturated in descending order according to it's saturation value on the factor, hence the researcher suggests naming this factor (excellence of human performance).

The researcher attributes this finding to the importance of concentrating on the human resources representing employees in the department from different classes, levels and specializations since it is considered the true pillar in which the modern organization rests upon, it controls the rest of the organization resources, so it must be concerned with these factors that may affect directly on achieving the institutional excellence of the department (appendix 9 ). 
It is shown from tables (7), (10) that the eignvalue for this factor was (5.39) and that the percent of the explained factorial variance was (10.58), and (7) items were saturated in descending order according to it's saturation value on the factor, hence the researcher suggests naming this factor (excellence of cognitive performance).

The researcher attributes this finding to the maximum importance of knowledge that based upon providing information and it's availability for all employees in the department as well as the beneficiaries to make use of the available information and the latent individual experiences in the minds of the employees leading to the ideal investment of the intellectual capital and transfer it a productive force contributing in developing the individual performance, rising the institution competence in a way to achieve the institutional excellence of the department (appendix 9) .

It is shown from tables (7), (12) that the eignvalue for this factor was (5.38) and that the percent of the explained factorial variance was (10.56), and (7) items were saturated in descending order according to it's saturation value on the factor, hence the researcher suggests naming this factor (excellence of leadership performance).

The researcher attributes this finding to considering leadership is one of the vital pillars in which different activities and business inside the organizations underlie. This appears prominently under organizations growth, it's large size, it's works divergence and complexity requiring the urgent need to cause the appropriate change and development in the form that guarantees continuity and excellence in performance and this task is not achieved but under a conscious management leadership possessing leadership skills so that it can move efforts, direct energies to achieve the best level of the institutional excellence (appendix 9) .

It is shown from tables (7), (13) that the eignvalue for this factor was (5.07) and that the percent of the explained factorial variance was (9.94), and (6) items were saturated in descending order according to it's saturation value on the factor, hence the researcher suggests naming this factor (excellence of service performance). 
The researcher attributes this finding to the necessity of interesting in the procedural operations that are necessary to present the services, since these services are considered the final product of the management process inside the work system in which it's properties should be concerned with to be appropriate with size and nature of the beneficiaries in a way enhancing the institutional performance inside the department arriving the institutional excellence(appendix 9 ).

It is shown from the previous table that the eignvalue for this factor was (4.63) and that the percent of the explained factorial variance was (9.08), and (7) items were saturated in descending order according to it's saturation value on the factor, hence the researcher suggests naming this factor (excellence of financial performance).

The researcher attributes this finding to the necessity of interesting in the procedural operations that are necessary to present the services, since these services are considered the final product of the management process inside the work system in which it's properties should be concerned with to be appropriate with size and nature of the beneficiaries in a way enhancing the institutional performance inside the department arriving the institutional excellence (appendix 9 ).

The researcher settled the final form of the factors that can affect the institutional excellence inside the department of youth and sport at Minia governorate through findings of the factorial analysis as follows (appendix 9 ):

\section{Responding the second question stating that :}

What are the factors necessary to detect the counterproductive work behaviors for youth and sport departments at Minia governorate?

The researcher conducted the factorial analysis by using SPSS Factorial analysis was conducted by the principle component method . After rotation, yielding (2) factors and by taking Guilford criterion (0.3), to select significant saturations statements were selected that were saturated on more than one factor with non convergent values by selecting major 
saturation and factors in which (3) statements and more were retained with a saturation value of a minimum (0.3) and the statements that got saturation less than (0.3) were deleted that guarantees better factorial purity for factors and the following is a description of these factors (appendix 9)

\section{It is shown from table}

(17) :That the eigenvalues for counterproductive work behaviors are greater than integer and that the factorial variance rates for the first factor explained (11.43), the second factor (11.02), the third factor accounted (33.58), the second factor (25.76), the total variance percent of the questionnaire for the derived seven factors was (59.34) (appendix 9).

It is shown from tables (17), (18) that the eignvalue for this factor was (6.38) and that the percent of the explained factorial variance was (33.58), and (12) items were saturated in descending order according to it's saturation value on the factor, hence the researcher suggests naming this factor (counterproductive work behaviors that target the organization) .

The researcher attributes this finding to the agreement of the study sample opinions on the danger of practicing these behaviors that may practice whether intentionally or unintentionally by some employees in the department of youth and sport that can lead to hurt the department productivity, emphasizing on the attempt to littleness or reducing the reasons that cause it that influence it!s performance directly (appendix 9) .

It is shown from tables (17), (19) that the eignvalue for this factor was (4.89) and that the percent of the explained factorial variance was (25.76), and (7) items were saturated in descending order according to it's saturation value on the factor, hence the researcher suggests naming this factor (counterproductive work behaviors targeting the individual) .

The researcher attributes this finding to the agreement of the study sample opinions on the importance of getting rid of these behaviors that can threat the department productivity, as well as top management trial to 
find the reasons leading to this that contribute in improving the employees performance at the department of youth and sport (appendix 9 ).

The researcher settled the final form that can form counterproductive work behaviors inside the department of youth and sport at Minia governorate through the findings of the factorial analysis as follows (appendix 9) :

\section{Responding the third question stating that :}

- Are factors of the institutional excellence available inside the department of youth and sport at Minia governorate ? (appendix 9)

\section{It is shown from table} (21) the following: The percent of mean response for the opinions of the study sample in statements of the first axis "operational performance excellence" ranged between (0.62: 0.71)

- All statements ranged between the minimum maximum confidence indicating it's verified moderately in operational performance excellence, the percent of the axis as a whole was (0.66) between minimum - maximum confidence indicating it's verified moderately in operational performance excellence .

The researcher attributes this finding to the limited ability of top management inside the department of youth and sport at Minia governorate on achieving procedural mechanisms and operational processes of work system that is appropriate with the goals of the institutional excellence indicating the existence of some deficiencies in applying components of excellence performance inside the department reflecting work internal systems negatively .

\section{It is shown from table} (22) the following: The percent of mean response for the opinions of the study sample in statements of the second axis "strategic performance excellence" ranged between (0.58: 0.69) -All statements ranged between the minimum - maximum confidence indicating it's verified moderately in strategic performance excellence, the statement (12) was less than minimum confidence indicating not verified and the percent of the axis as a whole 
was $(0.65)$ between minimummaximum confidence indicating it's verified moderately in strategic performance excellence .

The researcher attributes this finding to limitation of the strategic orientations by top management inside the department of youth and sport at Minia governorate in treating with the internal and external environment of work to achieve goals of continuous development to be appropriate with the goals of the institutional excellence, as well as inability to formulate a clear strategic vision and methods of declaring it inside and outside the department leading to the weakness of the institutional performance excellence in general and strategic performance in particular .

\section{(23) the following : The} percent of mean response for the opinions of the study sample in statements of the third axis "human performance excellence"ranged between (0.64: 0.73)

-All statements ranged between the minimum - maximum confidence indicating it's verified moderately in human performance excellence, the percent of the axis as a whole was $(0.68)$ between minimum maximum confidence indicating it's verified moderately in human performance excellence .

The researcher attributes this finding to the existence of some trials by top management inside the department of youth and sport at Minia governorate in treating with the employees in a way to achieve the competence and effectiveness , but these trials don't meet the required purpose to achieve the institutional excellence indicating a deficiency in achieving the institutional performance excellence .

It is shown from table
(24) the following :The percent of mean response for the opinions of the study sample in statements of the fourth axis "cognitive performance excellence ranged between (0.61: 0.73).

-All statements ranged between the minimum - maximum confidence indicating it's verified moderately in cognitive performance excellence, the percent of the axis as a whole was (0.56) between minimum- maximum 
confidence indicating it's verified moderately in cognitive performance excellence .

The researcher attributes this finding to the existence of deficiency in the ability of top management inside the department of youth and sport at Minia governorate on managing cognitions and information with an effective way that make it able of the cognitive excellence in performance that may reflect on excellence in the institutional performance as a whole.

It is shown from table (25) the following: The percent of mean response for the opinions of the study sample in statements of the fifth axis "leadership performance excellence ranged between ( 0.56: 0.69).

-All statements ranged between the minimum - maximum confidence indicating it's verified moderately in leadership performance excellence, the statements (34, 35) were less than minimummaximum confidence indicating not verified, the percent of the axis as a whole was (0.64) between minimummaximum confidence indicating it's verified moderately in leadership performance excellence .

The researcher attributes this finding to the absence of clear policies by top management inside the department of youth and sport at Minia governorate that emphasize on developing leadership skills that contribute in continuous guiding and improvement of performance so that the employees are able of excellence performance, as well as inability on enhancing delegation practices in a way that contributes in building leadership characters practically and scientifically, consequently inability to seek excellence in the institutional performance .

\section{It is shown from table} (26) the following : -The percent of mean response for the opinions of the study sample in statements of the sixth axis "service performance excellence" ranged between (0.59: 0.65).

-All statements ranged between the minimum- maximum confidence indicating it's verified moderately in service performance excellence, the statements (44) was less than 
minimum- maximum confidence indicating not verified,

the percent of the axis as a whole was (0.63) between minimum- maximum confidence indicating it's verified moderately in service performance excellence .

The researcher attributes this finding to the weakness of top management inside the department of youth and sport at Minia governorate to know creativity in using mechanisms to present the services available for the beneficiaries and it's inability to recognize the beneficiaries needs to achieve making the employees unable to present a distinctive service as well as not using modern technological methods in presenting the service indicating excellence weakness in service performance, consequently weakness of the institutional excellence.

It is shown from table (27) the following : - The percent of mean response for the opinions of the study sample in statements of the seventh axis " financial performance excellence " ranged between ( $0.66: 0.73$ ). -All statements ranged between the minimum- maximum confidence indicating it's verified moderately in financial performance excellence ,

the percent of the axis as a whole was (0.69) between minimum- maximum confidence indicating it's verified moderately in financial performance excellence .

- the percent of the questionnaire as a whole was (0.66) between minimummaximum confidence indicating it's verified moderately in the institutional excellence .

The researcher attributes this finding to the absence of financial policies inside the department of youth and sport at Minia governorate that provide an integrated system of the financial performance that can contribute effectively in the financial excellence and the most prominent features is developing an appropriate budget and provide the financial resources that suffice work needs, consequently weakness of the institutional excellence .

The percent of the questionnaire mean response as a whole (0.66) falling between the minimum- maximum 
confidence indicating the questionnaire verified moderately in the institutional excellence. The researcher attributes this finding that there are some trials by top management inside the department of youth and sport to arrive the institutional excellence, it may be typical and ineffective in the form that can achieve the institutional excellence inside the department, so it must be emphasized on practicing all the factors that can achieve the institutional excellence inside the department of youth and sport at Minia governorate and this is what Abdullah study (2017) confirmed

\section{Responding the fourth question stating :}

-Are there counterproductive work behaviors inside the department of youth and sport at Minia governorate? (appendix 9)

It is shown from table (28) the following :

-The percent of mean response for the opinions of the study sample in statements of the first axis "counterproductive work behaviors " ranged between (0.49: 0.65).
-All statements ranged between the minimum- maximum confidence indicating it's verified moderately in counterproductive work behaviors targeting the organization , statements $(11,12)$ was less than minimum confidence indicating not verified, the percent of the axis as a whole was (0.60) between minimummaximum confidence indicating it's verified moderately in counterproductive work behaviors.

The researcher attributes this finding that there are practices of counterproductive work behaviors targeting the organization practicing moderately as a result of a state of dissatisfaction about the performance of youth and sport department at Minia governorate in a way displays negative behaviors towards the department by some employees , not knowing duties and rights organizing work inside the department which are guides for their behavior, but there may be some supervision and control systems that prevent states of faking payment receipts to obtain further money more than what was agreed upon, or drinking drugs and 
alcohols in work that represent danger on the department.

It is shown from table (29) the following :

-The percent of mean response for the opinions of the study sample in statements of the second axis "counterproductive work behaviors" ranged between (0.54: 0.67).

-The statements $(13,14,15)$ ranged between the minimummaximum confidence indicating it's verified moderately in counterproductive work behaviors targeting the individual, statements $(15,16,17)$ were less than minimum confidence indicating not verified, the percent of the axis as a whole was (0.61) between minimummaximum confidence indicating it's verified moderately in counterproductive work behaviors targeting the individual .

- the percent of the questionnaire as a whole was (0.60) between minimum maximum confidence indicating it's verified moderately in counterproductive work behaviors inside the department of youth and sport at Minia governorate.

The researcher attributes this finding to the existence of some behavior practices inside the work against productivity targeting the individual practicing moderately as a result of unsatisfied management practices by top management of youth and sport department at Minia governorate affecting indirectly on personal relationships between employees which in turn reflected on them through feelings of work satisfaction and availability of mutual confidence and respect .

The researcher attributes this finding to employees possession in the department of the religious belief, adopting moral values in the way leading to committing with not commenting with racial, or religious or class observations towards a person in the work, insulting someone in work, embarrassing someone publicly in work.

\section{Responding the fifth} question stating that :

-Is there a statistically significant correlation between the institutional excellence and counterproductive work behaviors inside the department of youth and sport at Minia governorate? (appendix 9)

It is shown from table (30) the following: IThere is a statistically significant reverse correlation between factors of 
the institutional excellence and counterproductive work behaviors, as well as between total score of the institutional excellence and total score of counterproductive work behaviors inside the department of youth and sport at Minia governorate .

The researcher attributes this finding to the institutional excellence connection reversely, completely and closely with counterproductive work behaviors. Institutional excellence and what it includes of factors is one of the basic strong causes that contribute in restricting counterproductive work behaviors in the department of youth and sport at Minia governorate. The more the organization ability in achieving excellence in performance (operationalstrategic leadershipcognitive- human- servicefinancial) the more it is able to get rid of the negative behaviors that the employees can practice in the department of youth and sport that can form a clear and direct harm for the general interest inside the organization or it's members or the clients .

\section{Conclusions :}

In the light of the study findings the researcher concluded the following :

1- The findings of the factorial analysis for the questionnaire of the institutional excellence inside the department of youth and sport revealed that (7 factors were accepted and named according to the score of eignvalue, the percent of the explained variance as follows (Excellence of operational performance- Excellence of strategic performanceExcellence of human performance- Excellence of cognitive performanceExcellence of service performance- Excellence of financial performance )

2- The findings of the factorial analysis for the questionnaire of the institutional excellence inside the department of youth and sport revealed that (7) factors were accepted and named according to the score of eignvalue, the percent of the explained variance as follows (counterproductive work behaviors targeting the organization-

counterproductive work behaviors targeting the individual) 
3-The weakness of the institutional excellence factors availability inside the department of youth and sport at Minia governorate .

4-The availability of
counterproductive behaviors whether targeting the organization or the individual in work inside the department of youth and sport at Minia governorate .

5-Unavailability of counterproductive work behaviors related with the religious belief or moral values.

6- There is a statistically significant reverse correlation between the institutional excellence and counterproductive work behaviors inside the department of youth and sport at Minia governorate .

\section{Recommendations :}

1- The necessity of interesting in the factorial studies of this kind that adopt the idea of the factorial analysis for the management variables that can be analyzed to it!s basic components to rise sport organizations .

2- Emphasizing on providing the derived factors from the factorial analysis of the institutional excellence, working on achieving it to arrive the excellence performance inside work system .

3- Emphasizing on achieving the institutional excellence to limit counterproductive work behaviors (that target the organization and that target the individual ) .

\section{References}

\section{Arabic references:}

1- Abdullah, Ahmed Mohammed (2017): institutional excellence of youth and sport department in Alsharkia in the light of intellectual capital for sport specialists, the scientific journal of physical education and sport sciences, no. (81) (part 5), faculty of physical education for boys, Helwan university.

2- Alkhalifa, Mohammed AlGilani (2015) : the effect of managing knowledge on institutional performance in service establishment : a case study, General Coordination of national service ( Khartoum), A master thesis, the institute of researches and studies in Islamic world, Omdurman Islamic University.

3- Almerghani, Hala (2015): the effect of adopting standards of institutional excellence pattern in developing 
performance in government institutions at Sudan company for limited thermal generation, A master thesis, faculty of post graduates studies in Sudan university for sciences and technology.

4- Alnisour, Asmae Salem (2010): the effect of learning organization characteristics in achieving institutional excellence "an applied study in Jurdan Ministry of higher education and scientific research", A master thesis, faculty of business, Middle East university.

5- Alsayed, Reda (2007): excellence habits for the individuals of high management skills, Arabic united company for marketing and supplie.

6- Alsous, Nedaa Mohammed (2008) functional behavior, Oman, Jourdan, library of Arabic society.

7- Awad, Amer Mohammed (2015): the effect of the inspired leadership in counterproductive behaviors " a field study", The scientific journal of economy and commerce (3).

8- Elsalmi, Ali (2012): excellence management, patterns of contemporary management technicalities in knowledge age, Cairo, Dar Ghareeb.

9- Gaber, Abdel Multleb (2012): excellence in specific quality in higher education, Arabic Kingdom, Obeikan house for Publishing

10- Hamouda, Mona Ahmed (2009): a suggested frame for applying excellence management in universities, journal of financial and commercial researches, faculty of commerce, Suez Canal university.

11- Hassan, Ahmed Ali (2017): the role of management leadership and applying international work standards in coping counterproductive work behaviors, an applied study on the sector of pharmaceutical industries, unpublished doctoral thesis, faculty of commerce, Ain Shams university.

12- Hassan, Somia Kamal (2016): institutional excellence and it's effect in achieving the competitive advantage for business organizations "by applying on Unicharm corporate Ltd for health industries Kingdom of Saudi Arabia "A master thesis, faculty of management

Omdurman sciences, University, Sudan. foreign references: 13- Becker, T. E. \& Kernan, M. (2003): Matching commitment to supervisors and organizations to in-roleand extra-role performance, Human Performance, Vol. 16. 
14- Chang, K. \& Smithikari, C. (2010): Counterproductive Behavior at Work, an investigation Resource Management, 21(8).

15- Egelaar, S. J. D. (2014): The Applecation of the Excellence Model to Enhance Military Health Service Delivery and Performance Excellence, Doctoral Dissertation, South Africa, Rand Afrikaans University.

16- Gualandri, M. (2012): Counterproductive work behaviors and moral disengagement (unpublished doctoral dissertation), Sapienza Universita Di Roma.

17- Kelloway, E. K; Francis, L.; Prosser, M. \& Cameron, J. E. (2010): Counterproductive work behavior as protest. Human Resource Management Review, 20.

18- McShare, S. L. \& Glinow, M. A. (2007): Organizational behavior: Essentials, The McGraw Hill Companies.

19- Nafari, N.; Darbrin, $M$. \& Khalili, M. R. (2013): The study of the effect of organizational justice on antiproductive behavior of the staff of national Iranian gas company, Life Science Journal, Vol.10.

20- Rotundo, M. \& Sackett, P. R. (2012): The Relative importance of task, citizenship, and counterproductive performance to global ratings of job performance A policycapturing approach. Journal of Applied Psychology. 87(1).

21- Rotundo, M. \& Spector, P. E. (2010): Counterproductive work behavior and withdrawal. In J. L. Farr \& N. T. Tippins (Eds.), Handbook of employee selection, New York: Routledge/Taylor \& Francis Group.

22- Rotundo, M. \& Xie, J. L. (2008): Understanding the domain of counterproductive work behavior in China. The International Journal of Human Resource Management, 19 (5).

23- Sprung, J. M. (2011): Work locus of control as a moderator of the relationship between work stressors and counterproductive work behavior (unpublished master's thesis), the Graduate College of Bowling Green, State University.

24- Taylor, O. A. (2012): The relationship between culture and counterproductive workplace behaviors: A Meta analysis (unpublished doctoral dissertation), University of Western Ontario London, Ontario, Canada. 